\section{Does sacral agenesis predispose to spina bifida?}

SIR,

Families are presenting for genetic advice in regard to sacral agenesis (SA). We could find no good published studies which defined the genetics of SA or gave a recurrence risk. The relationship of SA to other forms of neural tube defects (NTD) has not been defined. The availability of intrauterine diagnosis for NTD makes it important to determine the strength of the association.

We ascertained 22 families who had had a child treated for SA at our hospital. Of these children, 15 had neurological dysfunction involving bowel, bladder, or limbs and seven had anorectal anomalies. One child was from a diabetic pregnancy and had multiple malformations. One family had two sibs with SA and associated anterior myelomeningocele, both index cases in our study. There were 14 males and nine females.

Birth order and miscarriage frequency did not differ from expectation. There were 40 sibs and 265 first cousins who were unaffected.

Sacral agenesis is a very heterogeneous entity. ${ }^{1}$ A number of published reports are consistent with an autosomal dominant pattern of inheritance ${ }^{2}$ and include families in which both sacral agenesis and spina bifida have occurred in different members. Occasional reports would be consistent with autosomal recessive inheritance. ${ }^{34}$ Maternal diabetes has been implicated in a number of studies ${ }^{3-8}$ and paternal diabetes has been noted in two reports. ${ }^{19} \mathrm{~A}$ number of reports indicate the concurrence of SA and NTD in the same patient ${ }^{14^{10-13}}$ (table). In addition, Anderson ${ }^{12}$ reported SA in nine of 73 patients with occult spinal dysraphism, and Dubowitz ${ }^{13}$ reported SA in six of 12 patients with a lipoma of the spinal cord.

TABLE Reported association of neural tube defects and sacral agenesis.

\begin{tabular}{|c|c|c|c|}
\hline & $\begin{array}{l}\text { Patients with } \\
\text { sacral agenesis }\end{array}$ & $\begin{array}{l}\text { Associated } \\
\text { myelomeningocele }\end{array}$ & $\begin{array}{l}\text { Associated } \\
\text { sacral lipoma }\end{array}$ \\
\hline Durham Smith 9 & 26 & 13 & \\
\hline Andrish et al10 & 17 & 3 & 2 \\
\hline Mariani ct al11 & 11 & 2 & 1 \\
\hline Blumel et $a l^{5}$ & 50 & 5 & \\
\hline \multicolumn{4}{|l|}{ White and } \\
\hline Glauber ${ }^{1}$ & 22 & 9 & \\
\hline
\end{tabular}

Although our own series of patients was too small to draw any conclusion about the relationship of SA to other NTD, the reports cited suggest that such a relationship exists. Until the strength of this association is defined, it would seem prudent to offer to families who have had a child with SA intrauterine diagnosis for NTD in a subsequent pregnancy with particular emphasis on high quality ultrasound.

It would require a much larger series of patients to establish an empirical recurrence risk but the occurrence of two affected sihs in this small series suggests a risk of recurrence of the order of 1 in 40 . Further studies of SA are needed.

\section{Ruth Magnus*, John G Rogers, AND ERIC A HAAN Birth Defects Research Institute, Royal Children's Hospital, Flemington Road. Parkville, Victoria 3052, Australia.}

\section{References}

1 White RI Glauber GT. Sacral agenesis: analysis of 22 cases. Urology 1976;8:521-5.

2 Fellous M, Boué J, Malbrunot C, et al. A five-generation family with sacral agenesis and spina bifida: possible similarities with the mouse T-locus. Am J Med Genet 1982;12:465-87.

${ }^{3}$ Stanley JK, Owen R, Koff S. Congenital sacral anomalies. J Bone Joint Surg (Br) 1979;61:401-9.

4 Robert JM, Pernod J, Bonnet R. L'agenesie sacrococcygienne familiale. J Genet Hum 1974;22:45-60.

5 Blumel J, Evans EB, Eggers GWN. Partial and complete agenesis or malformation of the sacrum with associated anomalies. J Bone Joint Surg (Am) 1959;41 :497-517.

${ }^{6}$ Stewart JM, Stoll S. Familial caudal regression anomalad and maternal diabetes. $J$ Med Genet 1979;16:17-20.

7 Abraham E. Lumbosacral coccygeal agenesis. $J$ Bone Joint Surg (Am) 1976;58:1169-71.

8 Pang D, Hoffman HJ. Sacral agenesis with progressive neurological defect. Neurosurgery 1980;7:118-26.

9 Durham Smith E. Congenital sacral anomalies in children. Aust NZJ Surg 1959;27:165-76.

10 Andrish A, Kalamchi A, MacEwen GD. Sacral agenesis: a clinical evaluation and its management, heredity and associated anomalies. Clin Orthop 1979;139:52-7.

11 Mariani AJ, Stern J, Khan AU, Cass AS. Sacral agenesis: an analysis of 11 cases and review of the literature. J Urol 1979;122:684-6.

12 Anderson FM. Occult spinal dysraphism: a series of 73 cases. Pediatrics 1975;55:826-35.

13 Dubowitz V, Lorber J, Zachary R B. Lipoma of the cauda equina. Arch Dis Child 1965;40:207-13.

*Dr Ruth Magnus died before the final preparation of this manuscript. 